\title{
ANÁLISE DE ROTA DE PENEIRAMENTO DE MINÉRIO DE FERRO NA ITM DA NAMISA S.A - UM ESTUDO DE CASO
}

\author{
F. SÃO JOSÉ ${ }^{1}$, M. L. TEIXEIRA JUNIOR ${ }^{2}$, C. A. PEREIRA ${ }^{3}$ \\ ${ }^{1}$ Programa de Pós-Graduação em Engenharia Mineral - UFOP, ${ }^{2}$ NAMISA/SA, ${ }^{3}$ Depto de Eng. de Minas - UFOP \\ pereiraufop@gmail.com
}

Submetido 03/04/2016 - Aceito em 27/07/2017

DOI: $10.15628 /$ holos.2017.4361

\section{RESUMO}

O mercado mundial de minério de ferro iniciou nova recuperação na década de 2000 , diante de um ciclo de expansão, chegando a atingir um ritmo superior a $70 \%$ de elevação de preços. Este fato viabilizou inúmeros projetos de mineração, principalmente no Brasil, nos quais jazidas antes desvantajosas economicamente passaram a ser empreendimentos de valor agregado. Dessa forma, pesquisas em todos os setores do processamento mineral intensificaram-se na busca por excelência no processo. No peneiramento, entendido como separação de sólidos em classes de tamanho e forma dos constituintes por meio do uso de peneiras, também houve procura por maior eficiência industrial. Assim, este trabalho investigou pontos de possíveis melhorias no peneiramento (primário e secundário) de uma mineradora de grande porte, exportadora de minério de ferro, buscando pontos de maximização do processo. Entre as principais observações destaca-se o indicativo de peneiras sobrecarregadas, levando a uma classificação ineficiente, fazendo com que produtos fiquem fora de especificação granulométrica e de teor, problemas operacionais e insegurança ocupacional. Sugestões de melhorias foram feitas por meio de mudanças nos equipamentos e no layout do processo.

PALAVRAS-CHAVE: Peneiramento Industrial, Minério de Ferro, Processamento Mineral.

\section{ROUTE ANALYSIS OF IRON ORE SINZING IN ITM FROM NAMISA S.A - A CASE STUDY}

\section{ABSTRACT}

The world market for iron ore began the new age marked by its recovery in the 2000 decade, before a cycle of expansion, reaching an accelerated growth rate of $70 \%$ in the prices. This fact made it possible several mining projects, mainly in Brazil, in which deposits were considered not economical have been given value. In this way, research in all sectors of mineral processing has intensified in the search for excellence. In the industrial sizing, a process to separate particles by size, usually to provide a downstream unit process with the particle size range suited to that unit operation there
\end{abstract}

was also demand industrial efficiency too. Thus, this study investigated the possible improvements in industrial sizing points (primary and secondary) of a big mining company, exporter of iron ore, looking for a maximization of the process. Among the main observations can highlight: sieves working overloaded, causing inefficient process, leaving products out of size specification and creating occupational problems. Suggestions for improvements were made through changes in equipment and process layout.

KEYWORDS: Industrial Sizing, Iron Ore, Mineral Processing. 


\section{INTRODUÇÃO}

O mercado de minério de ferro se supervalorizou na década de 2000, chegando a ter alta superior a $70 \%$ em seu valor em anos subsequentes (Pereira, 2012). Este fato viabilizou inúmeros projetos pelo mundo, principalmente no Brasil. Jazidas que antes eram dadas como desvantajosas passaram a ser consideradas como de alto valor agregado.

O simples fato de se produzir minério, seja de baixa ou alta qualidade, se tornou extremamente lucrativo. A frase era: "processar minérios a qualquer custo". Simplesmente compravam ou arrendavam-se jazidas, montavam-se plantas de beneficiamento sem critério técnico e dava-se início a uma nova produção, com mercado garantido.

No entanto, esta alavancada induziu corridas à elevação de produção, melhorias em qualidade, investimentos em Pesquisas \& Desenvolvimento e redução de custos com ganhos em indicadores de Manutenção e Operação de Processos. E todos os setores dentro da exploração mineral, desde a lavra, passando pelo beneficiamento mineral até o controle de qualidade obtiveram ganhos significativos.

No peneiramento, um processo mecânico de separação de partículas que se utiliza de uma superfície perfurada para tal e no qual as partículas com dimensões superiores à da abertura considerada tendem a ficar retidas na superfície e as de dimensões inferiores tendem a atravessar a mesma, não foi diferente.

A palavra eficiência em peneiramento industrial é empregada para expressar a avaliação do desempenho desta operação unitária, em relação à separação granulométrica ideal desejada. Ou seja, eficiência de peneiramento é definida como a relação entre a quantidade de partículas menores que a abertura da tela da peneira e que passam pela mesma e a quantidade de tais partículas existentes na alimentação. Um peneiramento é considerado comercialmente perfeito, quando sua eficiência atinge aproximadamente $95 \%$ e, para este valor, o fator de eficiência é considerado igual a 1,0 (Valadão e Araújo, 2007).

Industrialmente, uma boa eficiência de peneiramento situa-se entre 80 a 90\% (Chaves, 2003).

Wills (2004) de forma mais direta define eficiência no peneiramento como o grau de perfeição da separação de um material em duas frações, uma acima da abertura da malha e outra abaixo.

Contudo, nota-se a necessidade de adaptação constante às variações mineralógicas e de qualidade vivenciada pelas empresas do setor mineral. Onde a presença de finos e materiais friáveis torna-se o problema mais comum nesse âmbito.

O alvo de estudo deste trabalho será a Instalação de Tratamento de Minérios (ITM) da NAMISA S.A, empresa de grande porte produtora e exportadora de minério de ferro, localizada no município de Congonhas-MG e na qual se buscou levantar as possibilidades de melhorias nos processos de peneiramento e apresentar opções que minimizassem as interferências atualmente existentes levando a maximização da produção.

\subsection{Qualificação de um peneiramento industrial}

A fração de grossos alimentados à peneira (GA) e que chegam finalmente ao produto grosseiro (PG) é uma medida da eficiência de recuperação de grossos (EG) (Luz et. al., 2004). O esquema da Figura 1 representa uma malha de peneiramento e seus teóricos produtos. 


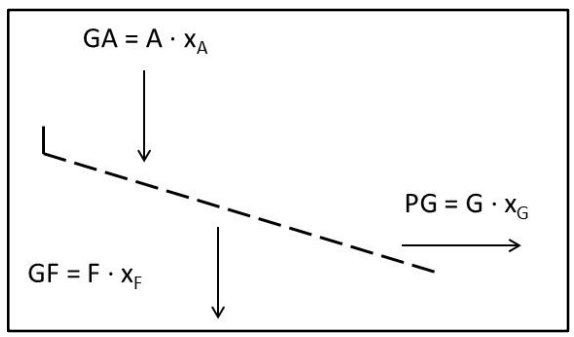

Figura 1 - Representação esquemática de um processo de peneiramento (Adaptado de Luz et. al., 2004).

$\mathrm{X}_{\mathrm{G}}$ : tamanho menor que a abertura da peneira existente nos grossos;

$\mathrm{x}_{\mathrm{A}}$ : tamanho menor que a abertura da peneira existente na alimentação;

$\mathrm{x}_{\mathrm{F}}$ : tamanho menor que a abertura da peneira existente nos finos.

Mas de maneira mais direta, e conforme já definido, a eficiência do peneiramento pode ser representada por uma relação simples, mostrada na Equação 1 (Luz et. al., 2004).

$\mathrm{E}=\frac{\mathrm{p}}{\mathrm{A} \cdot \mathrm{x}_{\mathrm{A}}} 100$

E: eficiência (\%);

p: passante $(t / h)$;

$\mathrm{X}_{\mathrm{A}}$ : tamanho menor que a abertura da peneira existente na alimentação;

A: alimentação $(t / h)$.

\section{METODOLOGIA}

A metodologia deste estudo de caso consistiu em:

- Averiguações da situação da Instalação de Tratamento de Minérios (ITM) por meio de mapeamento da planta de tratamento, amostragens periódicas, análises granulométricas (peneiras Tyler V2) de amostras dos produtos, análises químicas por absorção atômica, registros fotográficos, análises de layout para avaliação topográfica e avaliações das capacidades dos equipamentos de peneiramento;

- Sugestão de rota alternativa como proposta de melhorias.

\subsection{Amostragens}

As amostragens no peneiramento da ITM foram feitas a partir de coletas manuais em intervalos de 15 minutos no período de dois dias nas pilhas de estocagem dos produtos da empresa.

O fluxograma apresentado na Figura 2 ilustra o processo da ITM que envolve as etapas de peneiramento e foi utilizado neste trabalho para destacar os pontos de amostragem escolhidos. 


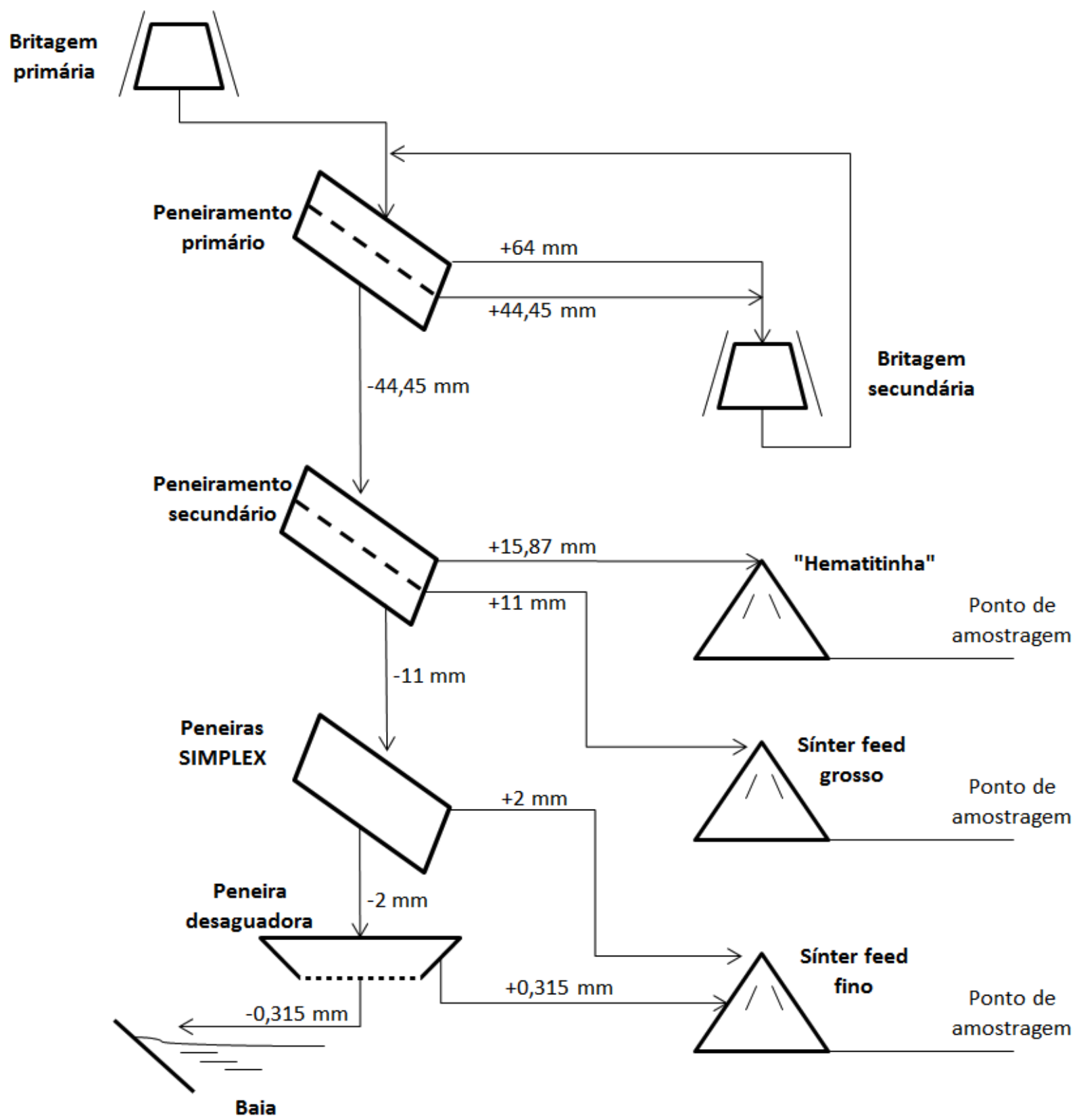

Figura 2 - Fluxograma simplificado da ITM/NAMISA S.A

Os pontos de amostragens localizaram-se nas pilhas de estocagem de seus respectivos produtos e as técnicas de coletas obedeceram todas as regras pertinentes à teoria da amostragem de granulados, com mão-de-obra qualificada e instrumentos adequados.

\subsection{Análise granulométrica}

Análises granulométricas foram feitas com as amostras coletadas nas pilhas de produtos da empresa. Escolheram-se malhas condizentes com as especificações dos produtos, ou seja $-44,45+$ 15,87 mm para "hematitinha", $-15,87+11,0 \mathrm{~mm}$ para sínter feed grosso e $-11,0+2,00 \mathrm{~mm}$ para sínter feed fino. Outras aberturas foram escolhidas somente para compor as séries de peneiramento, sem qualquer ligação direta com o processo industrial analisado. 
Após sequências de homogeneizações e quarteamentos, foram separados cerca de $300 \mathrm{~g}$ de material destinado aos peneiramentos a úmido.

\subsection{Análise do teor de ferro no produto sínter feed fino}

Foram escolhidas quatro amostras do produto sínter feed fino, devidamente preparadas, para quantificar o teor de ferro via absorção atômica. Esse procedimento possibilitou avaliar quanto os finos, arrastados para a parcela grossa, poderiam comprometer a qualidade do produto grosseiro.

\section{RESULTADOS E DISCUSSÃO}

\subsection{Indicativo para melhorias nos peneiramentos}

Nas operações do peneiramento secundário via peneira vibratória pode-se claramente observar que os fatores de produção por tonelada hora estavam próximos daqueles indicados em planejamento, mas indicando operações em máxima capacidade, dificultando uma classificação eficiente e gerando finos para o processo subsequente. A Figura 3 ilustra por meio de registro fotográfico o problema relatado como uma realidade na ITM.

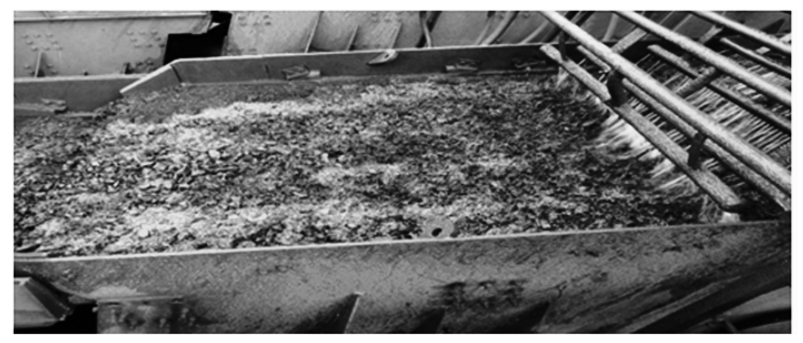

Figura 3 - Primeiro deck do peneiramento secundário sobrecarregado.

A consequência do fato apresentado (sobrecarga do peneiramento secundário) é a redução no indicador de disponibilidade física devido a quebras constantes de equipamentos, má classificação, redução na qualidade do produto com contaminação por faixa granulométrica e perda de recuperação, reprocessamento do produto granulado e transbordo de material sobre os pisos e passarelas, conforme Figura 4.

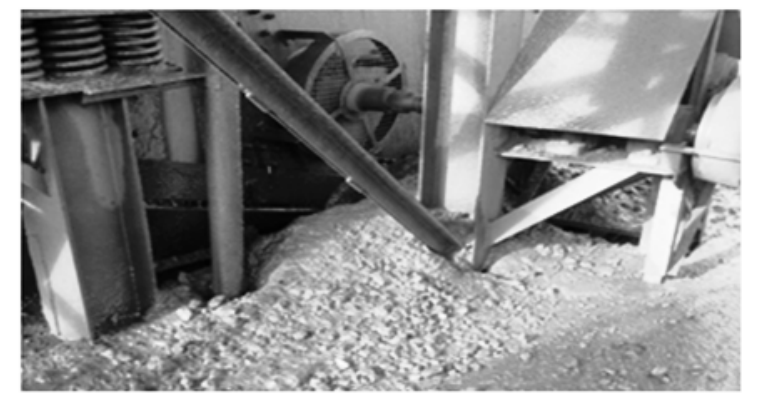

Figura 4 - Transbordo ocasionado por excesso de capacidade no peneiramento secundário.

Constatou-se que o peneiramento secundário trabalhou sobrecarregado gerando vários impactos como: quebras em excesso e deficiência na classificação. 


\subsection{Análise granulométrica dos produtos}

A Tabela 1 mostra os resultados da análise granulométrica feita com os materiais amostrados no peneiramento secundário da ITM antes de qualquer alteração nos sistemas.

Tabela 1 - Distribuição granulométrica das diferentes amostras do peneiramento secundário.

\begin{tabular}{c|c|c|c|c|c}
\hline \multicolumn{2}{c|}{ “Hematitinha" } & \multicolumn{2}{c|}{ Sínter feed grosso } & \multicolumn{2}{c}{ Sínter feed fino } \\
\hline$(\mathrm{mm})$ & $\%$ & $(\mathrm{~mm})$ & $\%$ & $(\mathrm{~mm})$ & $\%$ \\
\hline$+44,45$ & 0,0 & $+15,87$ & 0,0 & $+11,0$ & 0,0 \\
\hline$+15,87$ & 70,21 & $+11,00$ & 11,30 & $+4,75$ & 5,91 \\
\hline$+12,50$ & 18,02 & $+4,75$ & 69,75 & $+2,00$ & 44,58 \\
\hline$+6,35$ & 8,14 & $+1,00$ & 12,93 & $+1,00$ & 29,97 \\
\hline$+0,15$ & 3,63 & - & - & - & - \\
\hline
\end{tabular}

O resultado da análise granulométrica para produto denominado "hematitinha" situou-se fora de especificação $(-44,45+15,87 \mathrm{~mm})$, indicando a ineficiência do processo. Notou-se que $70,21 \%$ do produto eram compostos por material acima de $15,87 \mathrm{~mm}$, ou seja, os outros $29,79 \%$ eram finos, arrastados por ineficiência do peneiramento primário.

Para o sínter feed grosso $(-15,87+11,0 \mathrm{~mm})$, o resultado da análise granulométrica mostrou que o material se concentrou na malha de $4,75 \mathrm{~mm}(69,75 \%)$. E somando-se ao retido na malha de 1,0 $\mathrm{mm}$ esse se chega aos $82,68 \%$, confirmando as falhas no processo. A mesma tendência foi observada na malha intermediária para o peneiramento secundário visando à produção de sínter feed fino $(-11,0+2,00 \mathrm{~mm})$. Neste produto, menos de $50 \%$ do material estava regular quanto à especificação.

Comparando-se apenas os produtos sínter feed grosso e sínter feed fino (produtos considerados de maior valor agregado), notou-se que o peneiramento de sínter feed grosso foi mais eficiente do que para a produção de sínter feed fino, exemplificando a crescente dificuldade em tratar volumes mais finos. Finos dentro de uma etapa qualquer de processamento exige um controle mais preciso.

\subsection{Teor de ferro no produto sínter feed fino}

Após as confirmações do mau desempenho do peneiramento secundário, foram escolhidas quatro amostras representativas dos produtos sínter feed grosso e fino para analisar seu conteúdo de ferro. Tal procedimento permitiu averiguar a qualidade dos produtos, não apenas por granulometria, mas também pelo teor de ferro.

Para Fernandes (2003) a faixa teoricamente considerada sínter para os minérios de ferro compreende os tamanhos de $-1,00$ a $+0,15 \mathrm{~mm}$.

Já Padovezi et al. (2003) citam que os parâmetros de qualidade de um sínter feed é sua química global e a faixa granulométrica $+6,3 \mathrm{~mm},+1,0 \mathrm{~mm}$ e $-0,15 \mathrm{~mm}$.

Ou seja, a faixa granulométrica sínter feed é muito flexível por parte de empresas e pesquisadores.

Os tamanhos nos quais se analisou o teor de ferro foram escolhidos com base nos processos da ITM/NAMISA.

A Figura 5 apresenta os resultados de análise granuloquímica das quatro amostras escolhidas. Observou-se que as frações mais finas possuíam ligeiramente menos Fe, o que somado ao 
problema de eficiência de se peneirar esse tipo de material, sugere-se a necessidade de mais atenção em seu processo.

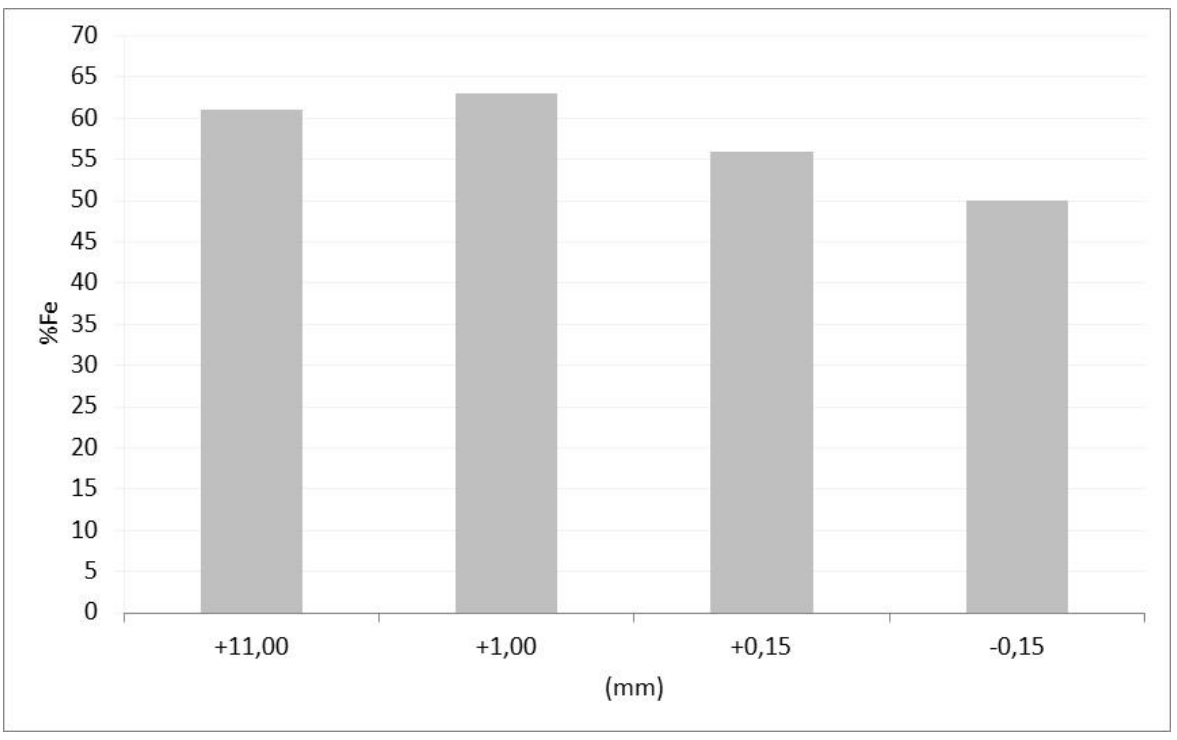

Figura 5 - Gráfico do resultado de análise granuloquímica.

\subsection{Sugestões para melhorias nos peneiramentos primário e secundário da ITM}

As percepções relatadas neste trabalho possibilitaram a sugestão de alguns pontos de melhorias nas etapas de peneiramento da ITM estudada. As sugestões concentraram-se na tentativa de impedir que finos em excesso prosseguissem para o peneiramento secundário. Tais sugestões resumem-se na lista abaixo:

- Troca da malha do primeiro deck de 64 para $30 \mathrm{~mm}$ no peneiramento primário, para destinar o retido à britagem secundária. Vale lembrar aqui que os problemas visualizados no peneiramento secundário são de origens no peneiramento primário;

- Aplicação de água no primeiro e segundo deck do peneiramento primário para redução de finos destinados à britagem secundária;

- Substituição da malha do segundo deck do peneiramento primário de 44,45 para $5 \mathrm{~mm}$ sendo o retido destinado também a britagem secundária da ITM.

Com a substituição da malha do segundo deck do peneiramento primário de 44,45 para $5 \mathrm{~mm}$ o passante de tal deck ( $-5 \mathrm{~mm}$ ) poderá, como outra alternativa, ser encaminhado por gravidade e por meio de tubulação, diretamente ao peneiramento terciário (Peneiras SIMPLEX) em que foi constatado por meio de análise visual, antecipadamente, que os decks das peneiras SIMPLEX encontravam-se abaixo de suas capacidades, possibilitando a manobra. Tal manobra evitaria o direcionamento de materiais abaixo de $5,0 \mathrm{~mm}$ para o britador secundário, podendo sobrecarrega-lo.

Dessa forma, propôs-se uma rota na qual se passaria a alimentar o peneiramento secundário com apenas $17 \%$ da alimentação atual e direcionaria $100 \%$ do passante do segundo deck do peneiramento primário $(-5 \mathrm{~mm})$ para as peneiras tipo SIMPLEX. A Figura 6 ilustra a alteração proposta utilizando um by-pass. 
Por fim, com as alterações propostas poderia destinar mais material para a britagem secundária ou para as peneiras SIMPLEX, aliviando o peneiramento secundário, ponto onde se constatava mais problemas operacionais, como sobrecarga, derramamento e paradas não programadas.

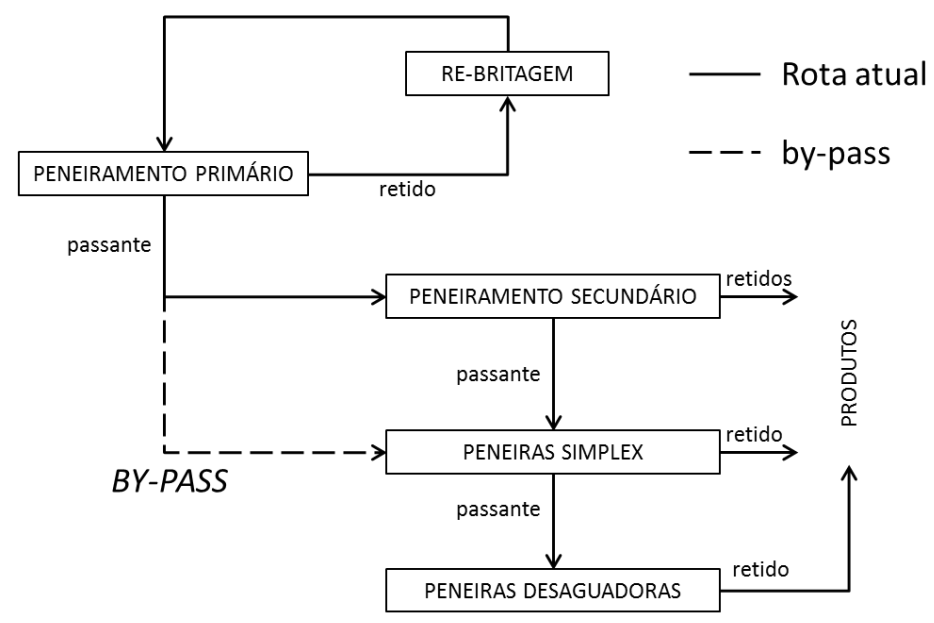

Figura 6 - Posicionamento do by-pass sugerido para ligar o peneiramento secundário às peneiras SIMPLEX.

\section{CONCLUSÕES}

Concluiu-se que o peneiramento secundário da referida unidade apresentou baixo desempenho no que tange a separação adequada dos tamanhos pretendidos. Notou-se que o problema tem origem no peneiramento primário, devido a escolha incorreta de malhas, e que se agravava nas frações mais finas.

As análises químicas dos constituintes do produto denominado sínter feed fino (produto de maior valor agregado) mostraram que a parcela mais fina $(-0,15 \mathrm{~mm})$ possui menor teor de ferro.

Por fim, salienta-se que a troca da malha do segundo deck do peneiramento primário de 44,45 para $5 \mathrm{~mm}$, com destinação do passante em $5 \mathrm{~mm}$ diretamente para o peneiramento SIMPLEX (uso do by-pass) pode ser um boa alternativa para reduzir ou até mesmo eliminar as dificuldades nos peneiramentos da unidade estudada, levando a ganhos de produtividade e organização do ambiente de trabalho.

\section{AGRADECIMENTOS}

Os autores agradecem à Universidade Federal de Ouro Preto, Fundação Gorceix, NAMISA/S.A., CAPES, Associação Brasileira de Metalurgia, Materiais e Mineração - ABM, FAPEMIG e ao CNPq.

\section{REFERÊNCIAS}

Pereira, S. A. C. (2012). O mercado de minério de ferro. Dissertação de mestrado, Universidade Federal de Minas Gerais, Belo Horizonte, Minas Gerais, Brasil.

Valadão, G. E. S., Araujo, A. C. (2007). Introdução ao tratamento de minérios. (1a ed.). Belo Horizonte: UFMG.

Chaves, A. P. (2003). Beneficiamento de Minérios. São Paulo: Cortez. 
Luz, A. B., Sampaio, J. A., Salvador, L. M. A. (2004). Tratamento de Minérios. (5a ed.). Rio de Janeiro: CETEM.

Wills, B. A. (2006). Mineral Processing Technology: An introduction to the practical aspects of ore treatment and mineral recovery. (7a ed.). Cornwall: Pergamon Press.

Fernandes, E. Z. (2003). Aplicação da caracterização tipológica ao planejamento de lavra de minério de ferro. Dissertação de mestrado, Universidade Federal de Minas Gerais, Belo Horizonte, Minas Gerais, Brasil.

Padovezi, A. D., Ferreira, A. D., Queiroz, L. A. (2003). Beneficiamento de minério de ferro - A importância da análise química e mineralogia na definição e melhorias de rotas de processo. Seminário de caracterização de ferrosos, CVRD. 